\title{
FLORA DE GRÃO-MOGOL, MINAS GERAIS: POLYGALACEAE ${ }^{1}$
}

\author{
MARIA DO CARMO M. MARQUES \& FÁTIMA S. GIL \\ Instituto de Pesquisas Jardim Botânico do Rio de Janeiro, Rua Pacheco Leão, 915, \\ 22460-030 - Rio de Janeiro, RJ, Brasil.
}

Bennett, A.W. 1874. Polygalaceae. In C.F.P. Martius, A.W. Eichler \& I. Urban (eds.) Flora brasiliensis. Frid. Fleischer. Leipzig, vol. 13, pars 3, p. 1-82, tab.1-30.

Brown, R. 1814. Polygaleae in Flinders. In A voyage to Terra Australis. G. \& W. Nicol. London, vol. 2, p. $542-544$.

Saint-Hilaire, A.F.C.P. 1829. Polygaleae. In A.F.C.P. Saint-Hilaire, A.H.L. Jussieu \& J. Cambessèdes (eds.) Flora Brasiliae meridionalis. Paris, vol. 2, pars 11-12, p. 5-75, tab. 83-96.

Marques, M.C.M. 1995. Polygalaceae. In B.L. Stannard (eds.) Flora of the Pico das Almas, Chapada Diamantina, Bahia, Brazil. Royal Botanic Gardens, Kew, p. 534-541.

Marques, M.C.M. 1997. Polygalaceae. In M.C.M. Marques \& H.F. Martins (eds.) Flora do Estado do Rio de Janeiro. Albertoa 4 (supl. 1): 130-200.

1. Ovário bilocular; fruto cápsula.

2. Inflorescências em panículas, sépalas caducas no fruto;

hilo da semente circundado por tufos de tricomas longos ........................................................................ Bredemeyera

3. Flores pediceladas; pedicelo 2-2,3 mm compr.; sépalas internamente pilosas e externamente carenadas para o ápice.

4. Lâmina foliar 5-12 cm compr., face superior pubérula somente ao longo da nervura central, a inferior totalmente pubérula; flores ca. $6 \mathrm{~mm}$ compr., pétalas laterais internas muito dilatadas na porção superior, 2,5-3 $\mathrm{mm}$ na sua maior largura; ovário piloso; fruto espatulado, pubérulo a glabrescente

B. floribunda

4'. Lâmina foliar 3-6 cm compr., esparsamente pubescente na face superior e densamente pubescente na face inferior; flores 3-3,2 mm compr.; pétalas laterais internas pouco dilatadas na porção superior $0,8-1,2 \mathrm{~mm}$ na sua maior largura; ovário e fruto glabros

3'. Flores sésseis a subsésseis; pedicelo até $0,5 \mathrm{~mm}$; sépalas internamente glabras

e externamente não carenadas para o ápice B. martiana

Inflorescências em racemos simples; sépalas persistentes no fruto, hilo da semente

não circundado por tufo de tricomas B. velutina

5. Carena com ápice simples; estilete terminado por uma cavidade pré-estigmática infundibuliforme

ou orbicular, desprovida de apêndice.

6. Flores 0,9-1,2 cm compr.; sépalas externas superiores livres entre si; disco circundando a base do ovário; estilete geniculado, tricomas nos bordos da cavidade pré-estigmática infundibuliforme; glândulas cilíndricas laterais à base do pecíolo e, freqüentemente na raque da inflorescência.

7. Lâmina foliar com as nervuras intersecundárias muito finas, formando reticulado laxo

e inconspícuo à vista desarmada; sépala externa inferior 3-4 x 3,5-4 mm; apêndice caruncular reto, alcançando $2 / 3$ até o comprimento total da semente..... P. insignis

7'. Lâmina foliar com as nervuras intersecundárias promínulas, principalmente no dorso formando reticulado denso e conspícuo à vista desarmada; sépala externa inferior 2,8-3 x 6-7 mm; apêndice caruncular encurvado na sua porção inferior, mais longo que o compr. da semente P. oxyphylla var. oxyphylla

6'. Flores 4-5 mm compr.; sépalas externas superiores conatas em sua maior parte; disco ausente, estilete curvo formando ângulo ca. $90^{\circ}$, tricomas anteriores

\footnotetext{
${ }^{1}$ Trabalho realizado conforme o planejamento apresentado por Pirani et al. (2003). Bol. Bot. Univ. São Paulo 21(1): 1-24.
} 
à cavidade pré-estigmática arredondada ; glândulas ausentes à base do pecíolo

e da raque da inflorescência P. violacea

5'. Carena com ápice cristado; estilete terminado por uma cavidade pré-estigmática cimbiforme-oblíqua, cuja extremidade superior tem um apêndice cristado.

8. Inflorescência congesta; corola persistente no fruto.

9. Ervas 10-30 cm alt.; folhas numerosas 1,6-2,5 cm x 0,5-1 cm, elípticas ou ovadas; bractéola central alcançando ou ultrapassando o ápice da flor

9'. Ervas 30-60 cm alt; folhas esparsas 1,2-2,5 cm x 1-1,5 mm, lineares ou estreitamente lanceoladas; bractéola central não alcançando o ápice da flor P.cuspidata var. cuspidata

Inflorescência laxa, corola caduca no fruto.

10. Lâmina foliar elíptica, lanceolada, ovada ou obovada com 3 nervuras proeminentes partindo da base, flores ca. $6 \mathrm{~mm}$ compr. P. hygrophila

0'. Lâmina foliar linear, com apenas a nervura central proeminente, flores 1,5-3,2 mm compr.

11. Sementes apendiculadas

11 '. Sementes não apendiculadas.

12. Folhas alternas, sementes com tricomas retos....

P.tenuis

12 '. Folhas verticiladas até $2 / 3$ do compr. do caule; semente com tricomas uncinados

P. glochidiata var. glochidiata

1'. Ovário unilocular, fruto sâmara Securidaca

13. Trepadeira 3-15 m alt; pecíolo 3-5 mm, lâmina 5-11,5 cm x 2,6-5,2 cm, adpresso-pubérula na face dorsal S. diversifolia

13'. Trepadeira 1-3 m alt.; pecíolo ca. 2 mm compr., lâmina 1,8-4 cm x 1-2,2 cm, tomentosa na face dorsal S. tomentosa

\section{Bredemeyera Willd.}

Arbustos escandentes. Folhas simples, alternas. Flores em panículas terminais densifloras, alvas a amareladas, 5-meras, sendo duas rudimentares presas ao dorso da baínha estaminal; ovário bicarpelar, bilocular, 1 óvulo por lóculo. Cápsula bivalvar, loculicida; sementes carunculadas, amarelo-seríceas; carúncula galeada, pequena, partindo do dorso e ao redor do hilo, longos tricomas branco-amarelados que alcançam, muitas vezes, a base do lóculo; endosperma carnoso, embrião contínuo.

\subsection{Bredemeyera floribunda Willd., Schriften Ges. Naturf.} Freunde Berlin 3: 411, tab.6. 1801.

Pecíolo 5-8 mm compr. tomentoso; lâmina 7-8,5 cm compr., 2,5-3 cm larg., estreitamente oblonga a elíptica, base obusa, ápice agudo; pubérula ao longo da nervura central da face ventral, totalmente pubérula na dorsal, cartácea. Panículas até $40 \mathrm{~cm}$ compr., raque e pedicelos tomentosos; pedicelo ca. $2 \mathrm{~mm}$ compr.; bractéolas caducas no botão; flores ca. $6 \mathrm{~mm}$ compr., sépalas internamente pilosas, externamente levemente carenadas para o ápice; pétalas laterais internas contraídas pouco acima da parte central, muito dilatadas na porção superior, ca. 2,5 mm na sua maior largura; ovário piloso, estilete falcado; cápsula espatulado-caudada, imatura tomentosa , madura glabrescente. (Fig. $1.1 \mathrm{a}-\mathrm{c}$ )

\section{Barreto et al. CFCR 12088 (SPF).}

América do Sul Tropical; no Brasil, ocorre de Roraima ao Paraná. Em Grão-Mogol, foi encontrado em capoeira, a ca. $700 \mathrm{~m}$ s.m., com flores e frutos em maio.

1.2. Bredemeyera martiana A.W.Benn. in Mart., Eichler \& Urb., Fl. bras. 13(3): 49. 1874.
Pecíolo ca. 4 mm compr., pubérulo; lâmina 4-4,5 cm compr., ca. 2,5 cm larg., elíptica, base aguda a obtusa; ápice obtuso a arredondado, face superior levemente pubescente, a inferior densamente pubescente, coriácea. Panículas até $20 \mathrm{~cm}$ compr., raque e pedicelos tomentosos; pedicelo ca. 1,8 $\mathrm{mm}$ compr., bractéolas persistentes na flor; flores 3-3,2 mm compr., sépalas internamente pilosas, externamente carenadas para o ápice, pétalas laterais internas pouco dilatadas na porção superior, 0,81,2 mm na sua maior largura; ovário glabro, estilete curvado em ângulo ca. $90^{\circ}$; cápsula espatulada, glabra. (Fig. $1.2 \mathrm{~d}$-g)

Barreto et al. CFCR 12057 (SPF); Mello Silva et al. CFCR 10887 (SPF); Rossi et al. CFCR 1010 (SPF).

Bahia, Minas Gerais e Espírito Santo. Em Grão-Mogol, foi encontrada em cerrado, a 650-950 m s.m., com flores e frutos em abril e maio.

1.3. Bredemeyera velutina A.W.Benn in Mart., Eichler \& Urb., Fl. bras. 13(3): 53. 1874.

Pecíolo ca 4-6 mm compr., pubescente-velutino, lâmina 5-8 cm compr., 2-4 cm larg., elíptica, base e ápice obtusos, face superior densamente pubérula, a inferior pubescente-ve- 
lutina, coriácea. Panículas até $30 \mathrm{~cm}$ compr., raque e pedicelos pubescente-velutinos, pedicelo ca. $0,5 \mathrm{~mm}$ compr., bractéolas persistentes na flor, flores 3,5-4,5 $\mathrm{mm}$ compr., sépalas internamente glabras, não carenadas para o ápice da face externa, pétalas laterais internas pouco dilatadas na porção superior, ovário glabro, estilete curvado em ângulo ca. $90^{\circ}$, cápsula obovada, glabra, por vezes levemente pubérula na base.
Pirani et al. CFCR 13017 (SPF)

Material adicional: Minas Gerais, São João da Chapada, Irwin 28591 (RB).

Bahia, Goiás e Minas Gerais. Em Grão-Mogol, foi encontrada no dossel da mata, a $950 \mathrm{~m} \mathrm{s.m}$, florescendo em junho.

\section{Polygala L.}

Ervas ou subarbustos; caules cilíndricos ou anguloso-alados. Folhas simples, alternas ou verticiladas até ca. 2/3 do caule, as demais alternas. Flores em racemos terminais ou axilares, alvas, alvo-esverdeadas, amarelas, róseas a roxas, 3 ou 5-meras, neste caso duas rudimentares, carena com ápice cristado ou não, ovário bicarpelar, bilocular; um óvulo por lóculo; sépalas persistentes no fruto. Cápsula, bivalvar, loculicida; sementes revestidas de tricomas retos ou uncinados; carunculadas ou não; endosperma carnoso, embrião contínuo.

\subsection{Polygala angulata DC., Prodr. 1: 328. 1824.}

Subarbustos 10-20 cm alt.; caules 5-anguloso-alados. Folhas alternas, sésseis, eretas, 1,2-2,5 cm compr., $0,5-1,2 \mathrm{~cm}$ larg., elípticas, base e ápice agudos a obtusos, coriáceas a membranáceas, 3 nervuras proeminentes partindo da base, glabras. Racemos laxos, pedicelo ca. 1,2 mm compr.; flores ca. $6 \mathrm{~mm}$ compr., róseo-arroxeadas; carena cristada; estilete curvo, terminado por cavidade pré-estigmática cimbiforme, levemente oblíqua cuja extremidade superior tem um apêndice cristado e a inferior um estigma globoso. Cápsulas ca. 3 mm compr., ca. 2,2 mm diâm., ovado-elípticas; sementes hirsútulas, carunculado-apendiculadas; apêndices 2, alargando-se para a base, geralmente conatos na face ventral, alcançando $2 / 3$ até total comprimento da semente. (Fig. 1 . 5 m-m')

Harley et al. $25016(\mathrm{SPF})$.

Bahia, Mato Grosso, Goiás, Minas Gerais e São Paulo. Em Grão-Mogol, está representada por $P$. angulata var. angulata, e foi encontrada em cerrado perturbado, com flores e frutos em outubro.

\subsection{Polygala cuspidata DC., Prodr. 1: 328. 1824.}

Ervas, 20-25 cm.alt.; caule anguloso-alado. Folhas, as inferiores 3-4 verticiladas, as demais alternas, sésseis ou curto-pecioladas, imbricadas, 1,6-2,5 cm compr., 0,5-1 cm larg., elípticas ou ovadas, base aguda ou obtusa, ápice agudo-mucronado, rígido-membranáceas. Racemos 2-2,5 cm compr., 1,4-1,6 cm larg., congestos, comosos no ápice, pedicelo $0,5-0,8 \mathrm{~mm}$ compr.; bractéolas persistentes, a central alcançando ou ultrapassando o ápice da flor; flores 4-4,5 mm compr., alvo-esverdeadas; carena cristada, corola persistente no fruto, estilete uncinado terminado por cavidade pré-estigmática cimbiforme-oblíqua cuja extremidade superior tem um apêndice cristado e a inferior um estigma globoso. Cápsulas 2,8-3 mm compr., 1,8-2 mm diâm., elípticas a suborbiculares, glanduloso-pontuadas; sementes glabrescentes, apendiculadas; apêndices 2 , livres, alcançando $2 / 3$ até total comprimento da semente. (Fig. 1.4 j-1)

Barros $52(\mathrm{RB})$

Bahia, Goiás, Minas Gerais e São Paulo. Em Grão-Mogol, está representada por $P$. cuspidata var. cuspidata, e é encontrada em campo cerrado, com flores e frutos, em abril.

2.3. Polygala glochidiata Kunth in Humb., Bonpl. \& Kunth, Nov. gen. sp. 5: 400. 1821.

Ervas $10-40 \mathrm{~cm}$ alt. Folhas verticiladas, até ca. $2 / 3 \mathrm{~cm}$ do caule, as demais alternas, sésseis ou subsésseis, 0,5-1,2 cm compr., 0,5-1,2 mm larg., lineares, agudo-mucronadas no ápice, subcarnosas. Racemos laxos, pedicelo 0,7-0,8 mm compr.; flores 2,2-3,2 mm compr., róseo-liláses, carena cristada, estilete curvo terminado por uma cavidade pré-estigmática, cimbiforme-oblíqua cuja extremidade superior tem um apêndice cristado e a inferior um estigma globoso. Cápsulas 1,2-2 mm compr., 0,7-1 mm diâm., elípticas a obovadas; sementes revestidas de tricomas uncinados, não carunculado-apendiculadas. (Fig. 1.9 w-y')

Bidá et al. CFCR 11955 (SPF); Campos et al. CFCR 13334 (SPF); Cavalcanti et al.,CFCR 8448 (RB, SPF); Cordeiro et al. CFCR 837 (SPF); Ferreira et al. 755 (RB); Freire-Fierro et al CFCR 12425 (SPF); Furlan et al. CFCR 707 (RB, SPF); Giulietti et al. CFCR 3434 (RB, SPF); CFCR 9817 (RB, SPF); Harley et al. 25133 (SPF); Lima et al. 965 (RB); Mamede et al.CFCR 3463 (RB, SPF); Pirani et al. CFCR 11416 (SPF), CFCR 10778 (RB, SPF), CFCR 12892 (SPF), Semir et al. CFCR 9603 (RB, SPF); Simonis et al. CFCR 4106 (RB, SPF); Zappi et al. CFCR 12915 (SPF).

Paraíba, Minas Gerais, Rio de Janeiro e Paraná. Em GrãoMogol, está representada por $P$. glochidiata var. glochidiata, e foi encontrada em campo rupestre, no cerrado, a 750-1050 m s.m., com flores e frutos o ano todo. 
2.4. Polygala harleyi Marques in Stannard, Fl. Pico das Almas: 538. 1995.

Subarbustos ca. $30-50 \mathrm{~cm}$. alt., caule cilíndrico e estriado. Folhas alternas, pecíolo 0,4-0,8 mm compr.; lâmina 0,51,3 cm compr., 0,8-1 mm larg., linear, agudo-mucronada no ápice, subcarnosa. Racemos terminais, laxos, 2-9 cm., pedicelos ca. 0,5 mm compr., flores ca. 2,5-2,8 mm compr., alvas a creme-esverdeadas, carena cristada, estilete uncinado, terminado por uma cavidade pré-estigmática cimbiforme-obliqua cuja extremidade superior tem um apêndice cristado e a inferior um estigma globoso. Cápsulas ca. 2,8 mm compr., ca. 1,2 mm diâm., suboblongas; sementes pubérulo-seríceas, ca. 2,6 mm compr., ca. 0,5 mm diâm., oblongas, carunculado-apendiculadas; 2 apêndices livres atingindo $1 / 2$ a 1/3 de seu comprimento. (Fig. $1.8 \mathrm{r}-\mathrm{v}$ )

Ferreira 701 et al. (RB); Martinelli 5790 (RB); Rossi et al. CFCR 1016 (RB, SPF).

Bahia e Minas Gerais. Em Grão-Mogol, está representada por P. harleyi var. intermedia Marques, sendo encontrada em cerrado, com flores e frutos em abril e maio.

2.5. Polygala hygrophilla Kunth in Humb., Bonpl. \& Kunth, Nov. gen. sp. 5: 395, tab. 508. 1821.

Erva $30-60 \mathrm{~cm}$. alt., caule anguloso-alado. Folhas, freqüentemente esparsas, alternas, às vezes verticiladas na base, subsésseis, 1,2-2,5 cm compr., 1-1,5 mm larg., lineares a estreitamente lanceoladas, agudo-mucronuladas no ápice, rígido membranáceas. Racemos 1-2 cm compr., 5-8 $\mathrm{mm}$ larg., congestos, inconspicuamente comosos no ápice; bractéolas persistentes, a central menor que a flor; flores ca. $2,8 \mathrm{~mm}$, róseas; carena cristada, estilete uncinado, terminado por uma cavidade pré-estigmática cimbiforme-oblíqua cuja extremidade superior tem um apêndice cristado e a inferior um estigma globoso, corola persistente no fruto. Cápsulas ca. 1,5-1,8 compr., orbiculares, esparsamente glanduloso-pontuadas; sementes glabescentes, carunculado-apendiculadas, 2 apêndices livres atingindo $1 / 3$ a $2 / 3$ do seu comprimento.

Irwin et al. $23357(\mathrm{~F})$.

Roraima, Amapá, Piauí, Bahia, Mato Grosso, Minas Gerais e São Paulo, e também na Venezuela. Em Grão-Mogol, foi encontrada a $950 \mathrm{~m}$ s.m., com flores e frutos em novembro.

2.6. Polygala insignis Chodat, Mém. Soc. Phys. Genève 31, pt. 2(2): 81, tab. 16, fig. 25. 1893.

Subarbusto ca. $60 \mathrm{~cm}$ alt.; ramos cilíndricos e estriados. Folhas alternas, glândulas cilíndricas laterais à base do pecíolo e na raque da inflorescência; lâmina 0,4-1 cm compr.,
1,5-3 cm larg., elíptica ou oblonga, obtusa na base e no ápice, por vezes retuso, rígido-membranácea a cartácea, nervuras secundárias muito finas, formando reticulado laxo e inconspícuo à vista desarmada. Racemos 3-5 cm compr., bractéolas caducas; pedicelos 2-2,2 mm compr., pubérulos, flores 1-1,3 $\mathrm{cm}$ compr, róseas; sépala externa inferior 3-4 mm compr., 3,5-4 mm larg.; carena com ápice simples, estilete geniculado, terminado por cavidade pré-estigmática infundibuliforme e ciliada nos bordos. Cápsula menor que as sépalas internas; sementes subtriangulares, pubérulas; apêndice caruncular reto, alcançando $2 / 3$ até o comprimento total da semente. (Fig. 1. h-i”)

Assis et al. CFCR 11565 (SPF)

Bahia, Minas Gerais e São Paulo. Em Grão-Mogol, foi encontrada ao sol em mata perturbada, com flores e frutos em novembro.

\subsection{Polygala oxyphylla DC, Prodr. 1: 331. 1824.}

Subarbustos ca. $1 \mathrm{~m}$ alt.; ramos cilíndricos e estriados. Folhas alternas, glândulas cilíndricas, laterais à base do pecíolo e na raque da inflorescência; lâmina 7-11 cm compr., 2-3,5 cm larg., estreitamente elíptica, aguda a longamente cuneada na base e cuspidada no ápice, rígido membránacea a cartácea, nervuras secundárias promínulas, principalmente no dorso, formando reticulado denso e conspícuo à vista desarmada. Racemos 2,5-4 cm compr., bractéolas caducas, pedicelos ca. $4 \mathrm{~mm}$ compr., pubérulos; flores ca. $9 \mathrm{~mm}$ compr., amarelas, sépala externa inferior 2,8-3 mm compr., 6-7 $\mathrm{mm}$ larg., carena com ápice simples, estilete geniculado, terminado por uma cavidade pré-estigmática infundibuliforme e ciliada em seus bordos. Cápsula do mesmo tamanho que as sépalas internas; sementes piriformes, tomentosas; apêndice caruncular encurvado na sua porção inferior, mais longo que o comprimento da semente. (Fig. 1.6 n-p)

Freire-Fierro et al. CFCR 12499 (SPF).

Bahia, Goiás e Minas Gerais. Em Grão-Mogol, está representada por $P$. oxyphylla var. oxyphylla, e foi encontrada entre 1000 a 1200 m. s.m., no interior de mata ciliar, com flores e frutos em dezembro.

\subsection{Polygala tenuis DC., Prodr. 1: 329. 1824.}

Ervas eretas 20-40 cm alt.; caule cilíndrico, tênue, simples ou ramificado para o ápice. Folhas alternas, sésseis, 3-6 mm compr., 0,2-0,5 mm larg., lineares. Racemos terminais, densifloros, 1-4 cm compr., pedicelos ca. 0,5 mm compr., flores 1,5-2 mm compr., amareladas, sépalas externas biglandulosas na base, não ciliadas nas margens, carena cristada, estilete curvo, terminado por cavidade pré-estigmática cimbiforme oblíqua cuja extremidade superior tem um apêndice 


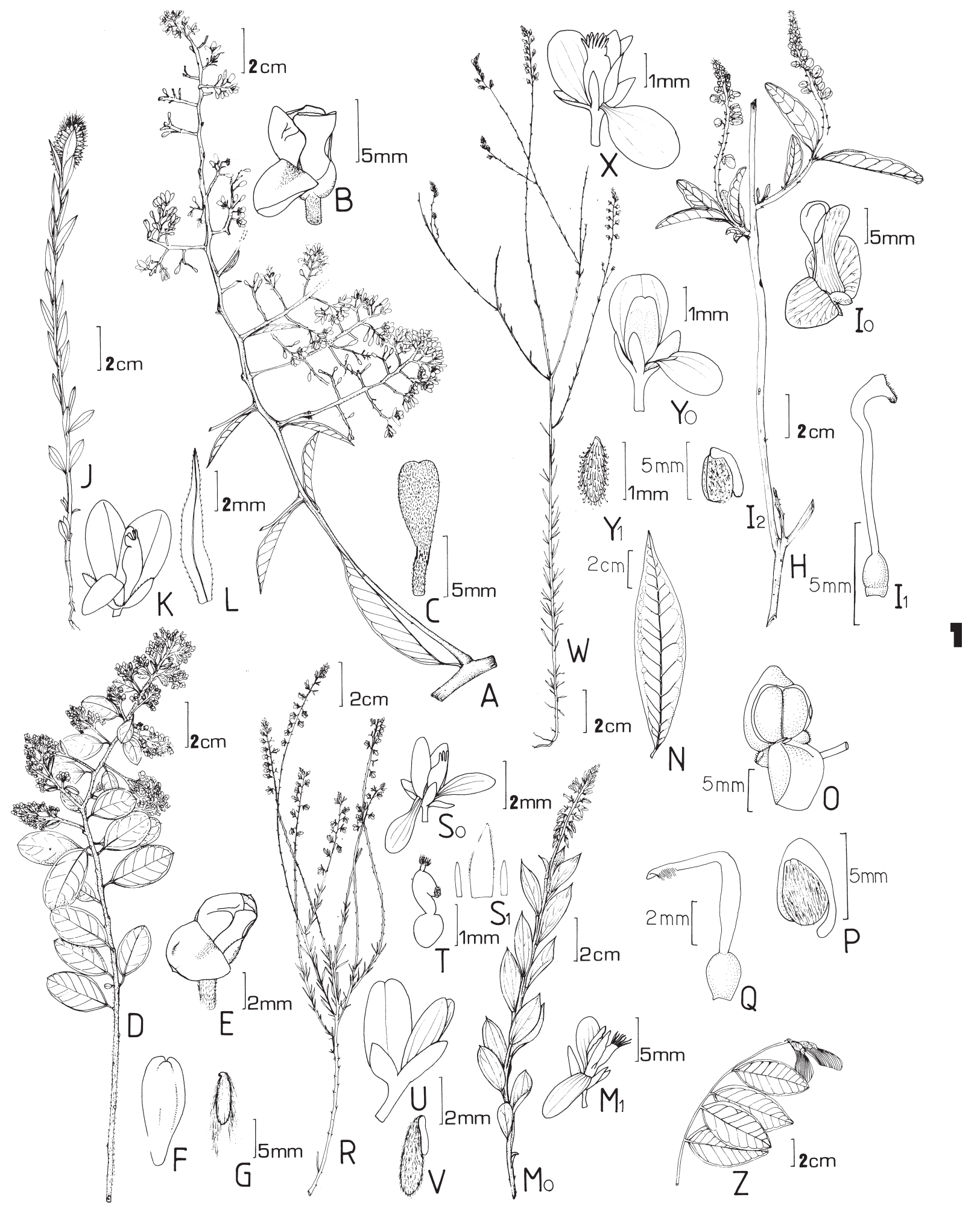

Fig. 1. POLYGALACEAE. 1. Bredmeyera floribunda: a. Ramo com inflorescência; b. Flor, destacando a pétala lateral muito dilatada para o ápice; c. Cápsula pilosa. 2. B. martiana: d. Ramo com inflorescência; e. Flor, destacando a pétala lateral pouco dilatada para o ápice; f. Cápsula glabra; g. Semente. 3. Polygala insignis: h. Ramo com inflorescência; i. Flor; i'. Gineceu; i”. Semente. 4. P. cuspidata var. cuspidata: j. Ramo com inflorescência. K. flor; 1. Bractéola central, maior que a flor. 5. P. angulata var. angulata: $\mathrm{m}$. Ramo com inflorescência; m'. Flor. 6. P. oxyphylla var. oxyphylla: $\mathrm{n}$. Folha; o. Cápsula com as sépalas persistentes; p. Semente. 7. P. violacea: q. Gineceu. 8. P. harleyi var. intermedia: r. Ramo com inflorescência; s. Flor; s'. Bractéolas; t. Gineceu; u. Cápsula com as sépalas persistentes; v. Semente. 9. P. glochidiata : w. Ramo com inflorescência; x. Flor; y. Cápsula com as sépalas persistentes; y'. Semente. 10. Securidaca diversifolia: $z$. Ramo frutífero. 
cristado e a inferior um estigma globoso. Cápsulas ca. 1,1 mm compr., ca. $1 \mathrm{~mm}$ diâm., suborbiculares, o dobro mais curtas que as sépalas internas; sementes mínimas subovóides, não apendiculadas, pubérulas.

Zappi et al. CFCR 13054 (SPF).

Bahia, Goiás, Mato Grosso, Minas Gerais, São Paulo e Paraná. Em Grão-Mogol, foi encontrada em solo arenosohumoso, úmido, ca. $850 \mathrm{~m}$ s.m, com flores e frutos em junho.

2.9. Polygala violacea Aubl., Hist. pl. Guiane 2: 735, tab. 294. 1775.

Ervas ca. $30 \mathrm{~cm}$ alt., ramos cilíndricos e estriados, revestidos de tricomas mistos, longos, eretos e curtos, encurvados, assim como pecíolo e raque. Folhas alternas, curto-pecioladas, 2,2-2,7 mm compr., 0,8-10 mm larg., lanceoladas, agudas na base, atenuadas no ápice, mem- branáceas. Racemos terminais, 1-5 cm compr., pedicelo ca. $2 \mathrm{~mm}$ compr., pubérulo, bractéolas caducas; flores ca. $4 \mathrm{~mm}$ compr., roxas, sépalas externas glanduloso-ciliadas nas margens; as superiores soldadas em sua maior parte; carena com ápice simples; estilete curvo, formando ângulo ca. $90^{\circ}$, tricomas anteriores à cavidade pré-estigmática arredondada. Cápsulas ca. $3 \mathrm{~mm}$ compr., ca. $2,5 \mathrm{~mm}$ diâm., elípticas, sementes oblongas, ca. 2,2 mm compr., revestidas de tricomas seríceos adpressos, carúncula córnea, prolongada na base por dois pequenos apêndices laterais corniculados, que se dirigem para a face ventral da semente e um posterior que se dirige para o dorso. (Fig. 1. $7 \mathrm{q})$

Freire-Fierro et al. CFCR 12553 (SPF).

Material adicional: São Paulo, Rio Claro, Cesar 168 (HRCB).

Américas Central e Sul, de ampla distribuição no Brasil, desde o Amapá até São Paulo. Em Grão-Mogol, foi encontrada em cerrado, com flores em dezembro.

\section{Securidaca L.}

Arbustos escandentes, folhas alternas, pecíoladas, pecíolo e pedicelo articulados, geralmente com duas glândulas laterais à base. Flores em racemos terminais ou axilares, simples ou bifurcados, róseo-purpúreas, 5-meras, duas rudimentares presas ao dorso da baínha estaminal, carena com ápice cristado, bractéolas caducas. Ovário bicarpelar, unilocular por aborto, uniovulado. Sâmara unialada; semente glabra, tegumento membranáceo, sem endosperma, embrião globoso muito próximo ao tipo conferruminado, com os cotilédones na maturidade fundidos em um só.

3.1. Securidaca diversifolia (L.) Black., Contr.Gray Herb. 47: 15. 1916.

Ramos, pecíolos, raque e pedicelos pubérulos, pecíolo ca. $3 \mathrm{~mm}$ compr., duas glândulas laterais à base, orbiculares e pontuado-sulcadas no ápice, lâmina ca. $6 \mathrm{~cm}$ compr., ca. $3 \mathrm{~cm}$ larg., elíptica ou ovada, base aguda a obtusa, ápice agudo, coriácea; face superior nítida, glabrescente a glabra, a inferior densamente pubérula. Racemos ca. $5 \mathrm{~cm}$ compr.; glândulas cilíndricas laterais à base do pedicelo; flores ca. $8,5 \mathrm{~mm}$ compr. Sâmara ca. $5 \mathrm{~cm}$ compr.; núcleo seminífero ca. $6 \mathrm{~mm}$ compr., ca. $5 \mathrm{~mm}$ diâm., suborbicular, reticulado, pubérulo; ala dorsal bem desenvolvida, ca. $4 \mathrm{~cm}$ compr., ca. $1,4 \mathrm{~cm}$ na sua maior largura, pubérula. (Fig. $1.10 \mathrm{z}$ )

Hatschbach et al 41493 (MBM).

Américas; no Brasil, é encontrada em quase todos os Estados. Em Grão-Mogol, foi encontrada com flores e frutos em outubro.
3.2. Securidata tomentosa A.St.-Hil. \& Moq. in A.St.-Hil., A.Juss. \& Cambess., Fl. Bras. mer. 2: 71, tab. 96. 1829.

Ramos, pecíolos, raque e pedicelos hirsuto-tomentosos; pecíolo 1,5-2 mm compr., duas glândulas estreito-cilíndricas, laterais à base, pouco evidentes; lâmina 1,8-3 cm compr., 1,1-1,8 cm larg., ovada, base arredondada ou subcordada, ápice obtuso, às vezes retuso, revoluta, ciliada nas margens, coriácea, face superior nítida, glabrescente a glabra, a inferior tomentosa. Racemos curtos, 1,5-3 cm compr.; glândulas laterais à base do pedicelo, inconspícuas; flores ca. $8 \mathrm{~mm}$ compr. Sâmara ca. 4 cm compr.; núcleo seminífero ca. $1 \mathrm{~cm}$ compr., ca. $8 \mathrm{~mm}$ diâm., suborbicular, levemente reticulado, velutino; ala dorsal bem desenvolvida, ca $3 \mathrm{~cm}$ compr., ca. 1,8 cm em sua maior largura, pubérula.

Martinelli 5796 (RB).

Bahia e Minas Gerais. Em Grão-Mogol, foi encontrada em cerrado, a 900 m. s.m., com flores e frutos em maio. 